\title{
EKSISTENSI PENDIDIKAN ISLAM \\ DALAM MENGHADAPI PERKEMBANGAN ILMU PENGETAHUAN DAN TEKNOLOGI (IPTEK)
}

\author{
Rumina \\ STAI Hasanuddin Pare Kediri \\ kliknana79@gmail.com
}

\section{Abstract}

Education as a learning activity or teaching and learning process can occur both inside and outside, as an educational activity can take place in the family, as well as in official educational institutions, activities or institutions are able to instill and make Islam as the basis for implementing education. The strategy implemented in facing the development of science and technology is the motivation of students'creativity towards the development of science and technology itself where Islamic values become a source of reference, educating skills, utilizing science and technology products, creating a strong link between religion and science and relationships with scientists who hold science and technology authority in their respective fields, Instill broad attitudes and insights into the future of humanity through the ability to interpret religious teachings. One of the priorities of national education development in relation to the development of the quality of human resources is related to improving the quality of each type and level of education so the existence of Islamic education in the face of the development of science and technology needs to be developed policies that emphasize improving the quality of human resources, intellectual intelligence, emotional intelligence, and spiritual intelligence.

Keyword: Pendidikan Islam, Ilmu pengetahuan, teknologi 


\section{A. PENDAHULUAN}

Pendidikan mempunyai peran yang sangat urgen untuk menjamin perkembangan dan kelangsungan kehidupan suatu bangsa, pendidikan juga menjadi tolak ukur kemajuan bangsa dan menjadi cermin kepribadian masyarakat. Dalam konteks ini Mohammad Noer Syam dalam bukunya filsafat pendidikan mengemukakan bahwa;

Hubungan masyarakat dengan pendidikan menampakkan hubungan korelasi positif, artinya pendidikan yang maju dan modern akan menghasilkan masyarakat yang maju dan modern pula, sebaliknya, pendidikan yang maju dan modern hanya ditemukan dan diselenggarakan oleh masyarakat maju dan modern." ${ }^{\prime}$

Zuhairini merumuskan sejarah pendidikan islam sebagai; (a) keterangan mengenai pertumbuhan dan perkembangan pendidikan Islam dari satu waktu kewaktu lain, sejak zaman kelahiran Islam sampai sekarang, (b) cabang ilmu pengetahuan yang berhubungan dengan pertumbuhan dan perkembangan pendidikan Islam, baik dari segi ide dan konsepsi maupun segi institusi dan oprasionalisasi sejak zaman Nabi Muhammad sampai sekarang.

Muhsin Riyadi dalam tulisannya tentang Eksistensi Pendidikan Agama Islam Di Tengah Kemajuan Ilmu Pengetahuan membahas tentang wahyu dan akal harus saling berkorelasi, sehingga Islam sebagai agama pembawa wahyu dan akal sebagai penggerak ilmu pengetahuan bisa seiring sejalan. ${ }^{2}$

Turun-naiknya atau maju-mundurnya dunia pendidikan Islam tidak terlepas dari hukum kausalitas yang meliputi pendidikan Islam, pembinaan dari Rosulullah, semangat ulama-ulama penguasa, sahabat-sahabat, dan umat Islam yang memajukan intelektual Islam,dan motivasi doktrin agama telah menciptakan kemajuan pendidikan Islam yang mengantarkan pendidikan Islam mencapai puncak keemasan.

Sebaliknya kecerobohan, kekacauan, serta kesalahan-kesalahan yang lain dalam sejarah ternyata berhasil menurunkan posisi kejayaan pendidikan Islam, semua ini tidak terlepas dari tindakan-tindakan umat Islam yang disengaja atau

\footnotetext{
Mohammad Noer Syam, Filsafat Pendidikan Islam Dan Dasar Filsafat Pendidikan Pancasila, hal; 348

2 Muhsin Riyadi, "Eksistensi Pendidikan Islam Di Tengah Kemajuan Ilmu Pengetahuan." Risalah: Jurnal Pendidikan Dan Studi Islam, no. 2 (September 2018) dalam https://jurnal.faiunwir.ac.id/index.php/Jurnal_Risalah/article/ view/88/108
} 
tidak disengaja. ${ }^{3}$

Pendidikan sebagai kegiatan belajar atau proses belajar mengajar dapat terjadi di dalam maupun diluar, sebagai suatu kegiatan pendidikan bisa berlangsung dalam keluarga, maupun dalam lembaga-lembaga pendidikan yang resmi, kegiatan atau lembaga tersebut mampu menanamkan dan menjadikan Islam sebagai dasar dalam penyelenggaraan pendidikan. Dari sini akan dapat kita bahas bab selanjutnya mengenai eksistensi pendidikan Islam dan pentingnya pendidikan Islam pada sekolah umum. ${ }^{4}$ yang akan mempunyai peranan yang sangat penting bagi proses perkembangan pendidikan pada saat sekarang ini.

\section{B. PENDIDIKAN DALAM PERSPEKTIF ISLAM}

Dalam Hazanah pemikiran pendidikan Islam, terutama karya-karya ilmiah berbahasa Arab, terdapat berbagai istilah yang dipergunakan oleh ulama dalam memberikan pengertian tentang "Pendidikan Islam"dan sekaligus diterapkan dalam konteks yang berbeda-beda. Menurut Langgulung, setidak-tidaknya tercakup dalam delapan pengertian, yaitu al-tarbiyah, al-diniyah (pendidikan keagamaan), ta'lim al-din (pengajaran agama), al-ta'lim al-diny (pengajaran keagamaan), al-ta'lim al Islamy (pengajaran keIslaman), tarbiyah al muslimin (pendidikan orang-orang Islam), al tarbiyah fi al Islam (pendidikan dalam Islam) al tarbiyah inda al-muslimin (pendidikan orang-orang Islam) dan al-tarbiyah al Islamiyah (pendidikan Islam).

Pengertian pendidikan bahkan lebih diperluas cakupanya sebagai aktifitas dan fenomena. Pendidikan sebagai aktivitas berarti upaya yang secara sadar dirancang untuk membantu seseorang atau sekelompok orang dalam mengembangkan pandangan hidup "bagaimana orang akan menjalani dan memanfaatkan hidup dan kehidupanya, sikap hidup, ketrampilan hidup, baik yang bersifat mental dan sosial"

Sedangkan pendidikan sebagai fenomena adalah peristiwa perjumpaan antara dua orang atau lebih yang dampaknya ialah berkembangnya suatu pandangan hidup, sikap hidup atau ketrampilan hidup pada salah satu atau beberapa pihak. Dalam konteks pendidikan Islam, berarti pandangan Islam, pandangan hidup, sikap dan ketrampilan tersebut harus bernafaskan atau dijiwai oleh ajaran dan nilai-nilai Islam yang bersumber dari al quran dan as sunnah

\footnotetext{
3 Hanun Asrohah, Sejarah Pendidikan Islam, hal: 10

${ }_{4}$ Khojin, Pendidikan Islam di Indonesia, hal :7
} 
atau al- hadits. ${ }^{5}$

Bertolak dari asumsi bahwa life is education and education is life, dalam arti pendidikan persoalan hidup dan kehidupan dan seluruh proses hidup dan kehidupan manusia adalah proses pendidikan, maka pendidikan Islam pada dasarnya hendak mengembangkan pandangan hidup Islami, yang diharapkan tercermin dalam sikap hidup dan ketrampilan hidup orang islam. ${ }^{6}$ Tujuan pendidikan Islam adalah untuk mencapai keseimbangan pertumbuhan kepribadian manusia ${ }^{7}$ yang tercermin dalam beberapa ciri yaitu:

1. Mengarahkan manusia agar menjadi kholifah Tuhan dimuka bumi dengan sebaik-baiknya, yaitu melaksanakan tugas-tugas memakmurkan dan mengolah bumi sesuai dengan kehendak Tuhan.

2. Mengarahkan manusia agar seluruh pelaksanaan tugas kekholifahannya di muka bumi dilaksanakan dalam rangka beribadah kepada Allah, sehingga tugas tersebut terasa ringan dilaksanakan.

3. Mengarahkan manusia agar berakhlak mulia, sehingga ia tidak menyalah gunakan fungsi kekholifahannya.

4. Membina dan mengarahkan potensi akal, jiwa dan jasmaninya, sehingga ia memiliki ilmu, akhlak dan ketrampilan yang semua ini dapat digunakan guna mendukung tugas pengabdian dan kekholifahannya.

5. Mengarahkan agar manusia agar dapat mencapai kebahagiaan hidup di dunia dan akhirat. ${ }^{8}$

Dari beberapa ciri pendidikan Islam diatas, bahwa sebenarnya tujuan itu cakupanya amat luas, Didalam tujuan tercakup berbagai masalah yaitu mencakup keinginan, proses, ramalan, dan maksud. Hal ini menggambarkan dengan jelas bahwa tujuan dalam praktenya menghendaki pilihan-pilihan yang dilakukan secara seksama terhadap berbagai alternatif yang ditawarkan. Kesalahan dalam memilih alternative dan perumusan suatu tujuan akan membawa hasil yang salah pula, itulah sebabnya suatu rumusan tujuan pendidikan tidak dapat dibuat secara sembarangan, atau dibuat tanpa mempertimbangkan berbagai kemungkinan yang akan dihasilkan dalam kegiatan pendidikan.

Menurut Mohammad Athiyah al-abrasy, pendidikan budi pekerti adalah

\footnotetext{
5 Muhaimin, paradiqma pendidikan Islam, hal :36-37

${ }^{6}$ Ibid hal : 39

7 Kemas Mas'ud Ali, "Integritas Pendidikan Agama Islam Terhadap Ilmu Pengetahuan Dan Teknologi." Tadrib: Jurnal Pendidikan Agama Islam, Vol. II, no. 1 (Juni 2016). dalam http://jurnal.radenfatah.ac.id/index.php/Tadrib/article/view/1158/977

8 Abuddin nata, Filsafat Pendidikan Islam, hal: 53
} 
jiwa dari pendidikan Islam, dan Islam telah menyimpulkan bahwa pendidikan budi pekerti dan akhlak adalah adalah jiwa pendidikan Islam. Mencapai suatu akhlak yang sempurna adalah tujuan sebenarnya dari pendidikan Islam. ${ }^{9}$

Pada definisi ini nampak bahwa gambaran manusia yang ideal yang harus dicapai melalui kegiatan pendidikan adalah manusia yang sempurna akhlaknya. Hal ini nampak sejalan dengan misi kerasulan Nabi Muhammad saw, yaitu untuk menyempunakan akhlak yang mulia.

\section{PARADIGMA PENDIDIKAN ISLAM}

Dalam paradigma ini, aspek kehidupan dengan sangat sederhana, dan kata kuncinya adalah dikotomi atau diskrit, segala sesuatu hanya dilihat dari dua sisi yang berlawanan, seperti laki-laki dan perempuan, ada dan tidak ada, madrasah dan non madrasah, pendidikan agama dan non keagamaan atau pendidikan agama dan pendidikan umum dan sebagainya.

Pandangan yang dikotonomis tersebut pada giliranya selanjutnya dikembangkan dalam melihat dan memandang aspek kehidupan dunia dan akhirat, kehidupan jasmani dan rohani, sehingga pendidikan Islam hanya diletakan pada aspek kehidupan akhirat saja atau kehidupan rohani saja.

Karena itu, pengembangan pendidikan Islam hanya berkisah pada aspek kehidupan ukhrowi yang terpisah dengan kehidupan duniawi, atau aspek aspek kehidupan rohani yang tepisah dengan kehidupan jasmani, pendidikan agama Islam hanya mengurusi persoalan ritual dan spiritual, sementara kehidupan ekonomi, politik, seni budaya, ilmu pengetahuan dan teknologi dan sebagainya dianggap sebagai urusan duniawi yang menjadi bidang garapan pendidikan umum, pandangan dikotonomis inilah yang menimbulkan dualisme dalam sistem pendidikan.

Umat Islam dididik dengan seperangkat ilmu pengetahuan atau mata pelajaran, salah satunya adalah mata pelajaran pendidikan agama yang mempunyai fungsi tersendiri yaitu:

1. Pengembangan dan peningkatan keimanan dan ketaqwaan.

2. Penyaluran bakat dan minat dalam mendalami agama

3. Perbaikan kesalahan

4. Pencegahan hal-hal negatif dari lingkunganya atau budaya asing yang berbahaya.

5. Sumber nilai atau pedoman hidup untuk mencapai kebahagiaan du-

9 Abuddin,hal :49 
nia dan akhirat.

6. Pengajaran atau penyampaian pengetahuan keagamaan. ${ }^{10}$

Jadi, pendidikan agama lebih menonjolkan fungsi moral dan spiritual atau dimensi afektif dari pada kognitif dan psikomotor, dalam arti dimensi kognitif dan psikomotor diarahkan untuk pembinaan afektif (moral dan spiritual) yang berbeda dengan mata pelajaran lainya.

\section{PENDIDIKAN ISLAM PADA SEKOLAH UMUM}

Pendidikan secara kultural pada umumnya berada dalam lingkup peran, fungsi dan tujuan yang tidak berbeda yang semuanya hidup dalam upaya yang bermaksud mengangkat dan menegakkan martabat manusia melalui transmisi yang dimilikinya, terutama dalam bentuk transfer of knowledge dan transfer of values.

Dalam konteks ini secara jelas juga menjadi sasaran jangkauan pendidikan islam,karena bagaimanapun pendidikan islam merupakan bagian dari sistem pendidikan nasional, sekalipun dalam kehidupan bangsa Indonesia tampak sekali perbedaan eksistensinya secra kultural. Tetapi secara kuat ia telah berusaha untuk mengambil peran yang kompetitif dalam setting sosiologi bangsa, walaupun tetap saja tidak mampu menyamai pendidikan umum, yang ada dengan otonomi dan dukungan yang lebih luas.

Sebagai pendidikan yang berlabel agama,maka pendidikan Islam memiliki transmisi spiritual yang lebih nyata dalam proses pengajaranya dibanding dengan pendidikan umum, kejelasan terletak pada kegiatan pendidikan Islam untuk mengembangkan seluruh aspek dalam diri anak didik secara berimbang, baik aspek intelektual, imajinasi dan keilmiahan, kultural serta kepribadianya. ${ }^{11}$

Disini antara ilmu pengetahuan dan pendidikan Islam tidak dapat dipisahkan, karena perkembangan masyarakat Islam, serta tuntutanya dalam membangun manusia seutuhnya sangat ditentuakn oleh kualitas dan kuantitas ilmu pengetahuan yaitu proses pendidikan.

Realitas membuktikan bahwa pendidikan agama (Islam) dan pendidikan umum selama ini sering diberikan batasan pengertian sebagai berikut:

1. Pendidikan agama yaitu penyelenggaraan pendidikan yang memberikan materi atau mata pelajaran agama, sedang pendidikan umum yaitu penyelenggaraanya pendidikan yang memberikan materi atau

\footnotetext{
${ }^{10}$ Muhaimin,hal :43

${ }^{11}$ Hasbullah,kapita selekta pendidikan islam,hal:5
} 
pelajaran umum.

2. Pendidikan agama sebagai lembaga pendidikan pada madrasah atau sejenisnya, sedangkan pendidikan umum sebagai lembaga pendidikan umum seperti SD, SMP, SMA, dan sejenisnya. ${ }^{12}$

Dari batasan diatas, nampaknya memberikan kesan adanya dikotomi antara bidang studi agama dan bidang studi umum atau adanya perbedaan yang jelas antara sekolah umum dengan sekolah agama. Dan terhadap dikotomi ilmu agama dan ilmu non agama pada dasarnya ilmu agama dan non agama hanya dapat dibedakan hanya untuk kepentingan analisis, bukan untuk dipisahkan apalagi dipertentangkan. Dalam sejarah tercatat ulama yang mendalami agama menjadi filosof dan dokter, seperti Ibnu Sina, atau lainnya. ${ }^{13}$

Kenyataan tersebut semakin tampak dengan keberadaan departemen yang membina, yaitu departemen pendidikan dan kebudayaan (Depdikbud) untuk lembaga pendidikan umum,dan departemen agama (depag) untuk lembaga pendidikan agama atau madrasah dan sejenisnya. Dari sini dapat kita perhatikan isi Undang-Undang Sistem Pendidikan Nasional (UU Sisdiknas) No. 2 tahun 1989.

1. Pada pasal 11 butir 2 disebutkan; pendidikan umum merupakan pendidikan yang mengtamakan perluasan pengetahuan dan peningkatan ketrampilan peserta didik dan pengkhususan yang diwujudkan pada tingkat-tingkat akhir masa pendidikan.

2. Pasal 11 butir 6 dinyatakan bahwa pendidikan keagamaan merupakan pendidikan yang mempersiapkan peserta didik untuk dapat menjalankan peranan yamh menuntut penguasaan pengetahuan khusus tentang ajaran agama yang bersangkutan.

3. pasal 39 ayat 2 disebutkan bahwa isi kurikulum setiap jenis,jalur dan jenjang wajib memuat pendidikan pancasila,pendidikan agama dan pendidikan kewarga negaraan,sementara itu pada ayat 3 lebih ditegaskan lagi,bahwa pendidikan agama merupakan salah satu isi kurikulum pendidikan dasar sebagai bahan kajian dan pelajaran dari 13 bahan kajian dan pelajaran yang ditetapkan.

Sebagai konsekuensi dari hal ini adalah terangkatnya status pendidikan agama tersebut dengan tidak dibedakan lagi dari pendidikan pada umumnya.

\footnotetext{
${ }^{12}$ Muwardi sutedjo dkk,kapita selekta pendidikan agama Islam,hal :23

${ }^{13}$ Masduki, "Pendidikan Islam Dan Kemajuan Sains: Historisitas Pendidikan Islam Yang Mencerahkan." Jurnal Pendidikan Islam Vol. IV, no. 2 (Desember 2015/1437). dalam http:// ejournal.uin-suka.ac.id/tarbiyah/index.php/JPI/article/view/1189/1085
} 
Dengan memperhatikan beberapa pasal tersebut, tampaknya memberikan gambaran yang lebih jelas lagi bagi kita tentang posisi pendidikan agama dan umum yang selama ini terkesan terpisah, kini lebih menyatu, dimana sebagai isi kurikulum, pendidikan agama menjadi muatan pokok, disamping pendidikan pancasila dan pendidian kewarga negaraan. Begitu juga sebagai suatu pendidikan Madrasah Ibtidaiyah dan Madrasah Tsanawiyah termasuk jenis pendidikan umum pada jemjang pendidikan.

Pencapaian pendidikan yang integralistik secara yuridis sudah dimulai sejak di berlakunya SKB tiga mentri pada tahun 1975 tentang peningkatan mutu pendidikan pada madrasah. Menurut SKB ini yang dimaksud madrasah ialah lembaga pendidikan yang menjadikan mata pelajaran agama Islam sebagai mata pelajaran dasar, yang diberikan sekurang-kurangnya 30\% disamping mata pelajaran umum. ${ }^{14}$

Akan tetapi dalam relitas sosial, polarisasi pendidikan masih sangat dirasakan, hal ini disebabkan karena program integralisasi kedua model pendidikan hanya diartikan dalam pendekatannya dan bersamaan dengan itu cenderung mengaburkan unsur-unsur lain seperti:

1. Keterpaduan proses belajar mengajar di tiga lingkungan pendidikan, baik lingkungan keluarga, sekolah maupun masyarakat, dari sini peran guru bukan hanya dituntut disekolahan saja tetapi juga dituntut dalam kegiatan pendidikan agama baik di rumah maupun di masyarakat.

2. Keterpaduan materi pendidikan agama, materi agama pendidikan agama harus dijadikan secra terpadu dengan materi pendidikan umum agar pendidikan yang disajikan selalu terkait secara fungsional dengan ilmu pengetahuan umum.

3. Keterpaduan penyelenggaraan antara departemen agama, departemen pendidikan dan kebudayaan dan lembaga-lembaga organisasi kemasyarakatan. ${ }^{15}$

\section{E. EKSISTENSI PENDIDIKAN ISLAM DALAM MENGHADAPI PERKEMBANGAN IPTEK}

Suatu masyarakat atau bangsa tidak akan memiliki keunggulan dan kemampuan daya saing yang tinggi, bila ia tidak mengambil dan mengembangkan

\footnotetext{
${ }^{14}$ M,Arifin,kapita selekta pendidikan islam dan umum,hal :48

${ }^{15}$ Hasbullah,sejarah pendidikan islam di Indonesia,hal:181
} 
Ilmu pengetahuan dan Teknologi, hal ini bisa dimengerti apabila setiap bangsa sekarang ini, berlomba-lomba serta bersaing secara ketat dalam penguasaan dan pengembangan iptek. Islam datang kedalam dunia yang sudah sangat beradab, sebuah dunia dimana Babel, Firaun, Yunani, Romawi, Bizantium, Achaemenian dan Sasanian yang berprestasi dibidang matematika, asronomi, kedokteran dan teknik sudah berjalan dan sangat besar. ${ }^{16}$

Strategi yang dijalankan pendidikan Islam dalam menghadapi tantangan modernisasi, perkembangan ilmu pengetahuan dan teknologi ialah:

1. Motivasi kreatifitas anak didik kearah pengembangan iptek itu sendiri dimana nilai-nilai Islam menjadi sumber acuan.

2. Mendidik ketrampilan,memanfaatkan produk iptek

3. Menciptakan jalinan yang kuat antara agama dan iptek dan hubungan yang akrab dengan para ilmuan, yang memegang otoritas iptek dalam bidang masing-masing.

4. Menanamkan sikap dan wawasan yang luas terhadap masa depan umat manusia melalui kemampuan menginterpretasikan ajaran agama. ${ }^{17}$

Jadi kesanalah pendidikan Islam seharusnya diarahkan, agar pendidikan Islam tidak hanyut terbawa arus modernisasi dan kemajuan iptek. Guru berperan sebagai penyaji informasi, pemberi contoh/teladan ,serta sumber nilai yang melekat dalam pribadinya. Sedangkan peserta didik menerima informasi dan merespon mempolakan pribadinya untuk menerima nilai-nilai kebenaran sesuai dengan kepribadian guru tersebut. Strategi inilah yang sesuai untuk pembelajaran nilai keTuhanan dan kemanusiaan, dimana dijabarkan didalam beberapa pendekatan pembelajaran yakni:

1. Pendekatan pengalaman, yakni memberikan pengalaman keagamaan kepada peserta didik dalam rangka menanamkan nilai-nilai keagamaan.

2. Pendekatan pembiasaan yakni memberi kesempatan kepada peserta didik untuk sesantiasa mengamalkan ajaran agamanya / akhlaqul karimah

3. Pendekatan emosional yakni usaha untuk menggugah perasaan dan emosi peserta didik dalam meyakini, memahami dan menghayati akidah Islam serta member motivasi agar peserta didik ikhlas menga-

16 "Pemanfaatan Teknologi Informasi Dalam Peningkatan Mutu Pendidikan Islam Di Madrasah." Mudarrisa: Jurnal Kajian Pendidikan Islam Vol. 6 , no. 1 (Juni 2014) dalam https://mudarrisa.iainsalatiga.ac.id/index.php/mudarrisa/article/view/758

17 Ibid,hal :13 
malkan ajaran agamanya .khususnya yang berkaitan dengan akhlakul karimah.

4. Pendektan rasional, yakni usaha untuk memberikan peranan kepada rasio (akal) dalam memahami dan menerima kebenaran ajaran agama.

5. Pendekatan fungsional, usaha menyajikan ajaran agam Islam dengan menekankan kepada segi kemanfaatanya bagi peserta didik dalam kehidupan sehari-hari sesuai dengan tingkat perkembanganya.

6. Pendekatan keteladanan yakni menyuguhkan keteladanan, baik yang langsung melalui penciptaan kondisi pergaulan yang akrab antara personal sekolah, prilaku pendidik dan tenaga kependidikan lain yang mencerminkan akhlak terpuji, maupun yang tidak langsung melalui suguhan ilustrasi berupa kisah-kisah keteladanan. ${ }^{18}$

Sayyed Hossein Nasr dalam bukunya "Islam and the Challenge of the 21 Century" (1993) mengemukakan sejumlah tantangan yang dihadapi oleh dunia pendidikan pada abad 21 yaitu (1) krisis lingkungan, (2) tatanan global (3) post modernism, (4) sekularisasi kehidupan, (5) krisis ilmu pengetahuan dan teknologi (6) penetrasi nilai-nilai non islam, (7) citra islam, (8) sikap terhadap kebudayaan orang lain, (9) feminisme, (10) hak asasi manusia, dan (11) tantangan internal. ${ }^{19}$

Jadi dalam hal ini perkembangan pendidikan Islam tidak dapat ditangani secara setengah-setengah, tetapi memerlukan pemikiran pengembangan yang utuh sebagai konsekuensi dari identitasnya sebagai sekolah umum yang bercirikan Islam. Dalam menghadapi perkembangan iptek perlu dikembangkan kebijakan yang menekankan pada peningkatan kualitas SDM. Menurut wardiman (1994) manusia yang berkualitas itu setidak-tidaknya mempunyai dua kompetensi yaitu kompetensi bidang imtaq (iman dan taqwa) dan iptek (ilmu pengetahuan dan tenologi). ${ }^{20}$

Pesatnya perkembangan IPTEK di era globalisasi, pendidikan Islam harus bisa menyiapkan generasi bangsa yang siap bersaing dan memiliki cara berpikir secara komprehensif yang senantiasa dijiwai nilai-nilai agama yang konsisten (teologishumanistik) dalam rangka mengantisipasi pengaruh perkembangan IPTEK yang berdampak kurang baik terhadap moralitas dan kemunduran per-

\footnotetext{
${ }^{18}$ Muhaimin. Arah baru pengembangan pendidikan islam, hal: 94

${ }^{19}$ Ibid, 197

${ }^{20}$ Wardiman Joyonegoro, Potensi serta peran pendidikan dan pengajaran pondok pesantren dalam system pendidikan nasional," Makalah ,disajikan pada musyawarah nasional IV RMI di PP Ash-shiddiqoyah, 1 February 1994.
} 
adaban bangsa. ${ }^{21} \mathrm{Hal}$ itu diperlukan adanya 1) Kecerdasan intelektual, yaitu kecerdasan yang dikaitkan dengan kecerdasan otak. 2) Kecerdasan emosional merupakan kemampuan untuk memotivasi diri sendiri, yang membuat seseorang dapat bertahan dalam menghadapi frustasi, dapat mengendalikan dorongan hati dan menjaga beban setres. 3) Kecerdasan spiritual merupakan pikiran terilhami, sebagai pengetahuan akan kebenaran yang paling dalam, kecerdasan ini mampu membuat orang hidup lebih toleran, terbuka, jujur dan berlaku adil.

\section{F. PENUTUP}

Dari uraian diatas, apabila kita soroti dari fenomena pengembangan pendidikan islam disekolah atau perguruan tinggi umum nampaknya sangat bervariasi dalam arti ada yang cukup puas dengan pola tersebut dan sebaliknya.Kebijakan tentang pembinaan pendidikan agama islam secara terpadu disekolah umum misalnya menghendaki agar pendidikan agama dan sekaligus para guru agamanya mampu memadukan antara mata pelajaran agama dengan pelajaran umum.

Pendidikan Islam di Indonesia yang sedang berlangsung saat ini adalah sebagai subsistem pendidikan nasional, secara implisit akan mencerminkan cirri-ciri kualitas manusia Indonesia seutuhnya, dengan demikian keberhasilan pendidikan Islam akan membantu terhadap keberhasilan pendidikan nasional, juga sebaliknya keberhasilan pendidikan nasional secara makro turut membantu pencapaian tujuan pendidikan Islam. Oleh sebab itu keberadaan lembaga pendidikan Islam oleh pemerintah dijadikan mitra untuk mencerdaskan kehidupan bangsa.

Strategi yang dijalankan dalam menghadapi perkembangan iptek adalah Motivasi kreatifitas anak didik kearah pengembangan iptek itu sendiri dimana nilai-nilai Islam menjadi sumber acuan, mendidik ketrampilan, memanfaatkan produk iptek, menciptakan jalinan yang kuat antara agama dan iptek dan hubungan yang akrab dengan para ilmuan yang memegang otoritas iptek dalam bidang masing-masing, Menanamkan sikap dan wawasan yang luas terhadap masa depan umat manusia melalui kemampuan menginterpretasikan ajaran agama. Jadi, dalam menghadapi perkembangan iptek perlu dikembangkan kebijakan yang menekankan pada peningkatan kualitas SDM.

${ }^{21}$ Zainal Mustakim,"Pendidikan Islam, Globalisasi Teknologi Informasi, dan Moralitas Agama." FORUM TARBIYAH Vol. 11, no. 1 (Juni 2013) dalam http://e-journal.iainpekalongan. ac.id/index.php/forumtarbiyah/article/view/460 


\section{DAFTAR PUSTAKA}

Ali, Kemas Mas'ud. "Integritas Pendidikan Agama Islam Terhadap Ilmu Pengetahuan Dan Teknologi." Tadrib: Jurnal Pendidikan Agama Islam II, no. 1 (Juni 2016).

Arifin, M. Kapita Selekta Pendidikan (Islam Dan Umum). Jakarta: Bumi Aksara, 1993.

Asrohah, Hanun. Sejarah Pendidikan Islam. Jakarta: Logos Wacana Ilmu, 1999.

Budiman, Agus. "Teknologi Pendidikan Dan Dinamika Pendidikan Islam." At Ta'dib: Journal Of Pesantren And Education 3, no. 2 (Sya'ban 1428).

Hasbullah. Sejarah Pendiidkan Islam. Jakarta: Rajawali Press, 1995.

Masduki. "Pendidikan Islam Dan Kemajuan Sains: Historisitas Pendidikan Islam Yang Mencerahkan." Jurnal Pendidikan Islam IV, no. 2 (Desember 2015/1437).

Muhaimin. Arah Baru Pengembangan Pendidikan Islam. Bandung: Nuansa, 2003.

, Paradigma Pendidikan Islam. Bandung: PT. Remaja Rosda Karya, 2001.

Mustakim, Zainal. "Pendidikan Islam, Globalisasi Teknologi Informasi, dan Moralitas Agama." FORUM TARBIYAH 11, no. 1 (Juni 2013).

Muwardi Sutedjo, dkk. Materi Pokok Kapita Selekta Pendidikan Agama Islam, PPGI 2463/2 SKS Modul 1-6. Jakarta: Ditjen Pembinaan Kelembagaan Agama Islam, 1993.

Nata, Abudin. Filsafat Pendidikan Islam. Jakarta: Gaya Media Pratama, 2005.

Nugroho, Muhammad Aji. "Pemanfaatan Teknologi Informasi Dalam Peningkatan Mutu Pendidikan Islam Di Madrasah." Mudarrisa: Jurnal Kajian Pendidikan Islam (Prodi Pendidikan Guru Madarasah Ibtidaiyah (PGMI) IAIN Salatiga) 6 , no. 1 (Juni 2014).

Riyadi, Muhsin. "Eksistensi Pendidikan Islam Di Tengah Kemajuan Ilmu Pengetahuan." Risalah: Jurnal Pendidikan Dan Studi Islam (Fakultas Agama Islam Universitas Wiraloda Indramayu) 4, no. 2 (September 2018).

Syam, Muhammad Noer. Filsafata Pendidikan Dan Dasar Filsafat Pendidikan 